\title{
TU/e EN⿴HONE

\section{Single-step solution processing of small-molecule organic semiconductor field-effect transistors at high yield}

\section{Citation for published version (APA):}

Yu, L., Li, X., Pavlica, E., Loth, M. A., Anthony, J. E., Bratina, G., Kjellander, B. K. C., Gelinck, G. H., \& Stutzmann, N. (2011). Single-step solution processing of small-molecule organic semiconductor field-effect transistors at high yield. Applied Physics Letters, 99(26), 1-3. [263304]. https://doi.org/10.1063/1.3673280

DOI:

$10.1063 / 1.3673280$

Document status and date:

Published: 01/01/2011

\section{Document Version:}

Publisher's PDF, also known as Version of Record (includes final page, issue and volume numbers)

\section{Please check the document version of this publication:}

- A submitted manuscript is the version of the article upon submission and before peer-review. There can be important differences between the submitted version and the official published version of record. People interested in the research are advised to contact the author for the final version of the publication, or visit the $\mathrm{DOI}$ to the publisher's website.

- The final author version and the galley proof are versions of the publication after peer review.

- The final published version features the final layout of the paper including the volume, issue and page numbers.

Link to publication

\section{General rights}

Copyright and moral rights for the publications made accessible in the public portal are retained by the authors and/or other copyright owners and it is a condition of accessing publications that users recognise and abide by the legal requirements associated with these rights.

- Users may download and print one copy of any publication from the public portal for the purpose of private study or research.

- You may not further distribute the material or use it for any profit-making activity or commercial gain

- You may freely distribute the URL identifying the publication in the public portal.

If the publication is distributed under the terms of Article 25fa of the Dutch Copyright Act, indicated by the "Taverne" license above, please follow below link for the End User Agreement:

www.tue.nl/taverne

Take down policy

If you believe that this document breaches copyright please contact us at:

openaccess@tue.nl

providing details and we will investigate your claim. 


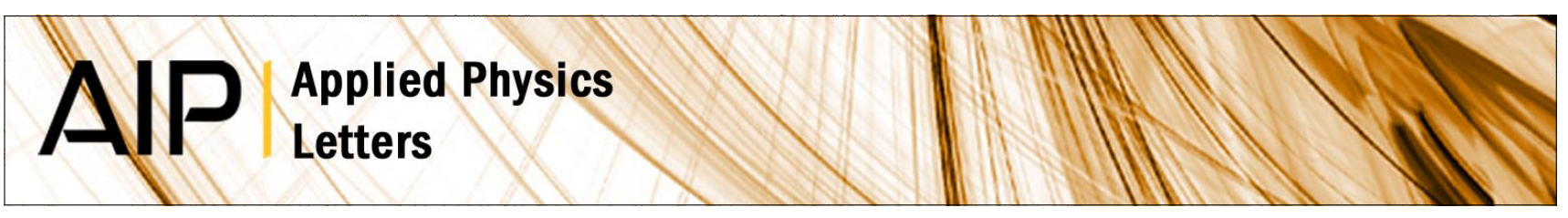

\section{Single-step solution processing of small-molecule organic semiconductor field-effect transistors at high yield}

Liyang Yu, Xiaoran Li, Egon Pavlica, Marsha A. Loth, John E. Anthony et al.

Citation: Appl. Phys. Lett. 99, 263304 (2011); doi: 10.1063/1.3673280

View online: http://dx.doi.org/10.1063/1.3673280

View Table of Contents: http://apl.aip.org/resource/1/APPLAB/v99/i26

Published by the American Institute of Physics.

\section{Related Articles}

Dependence of carbon nanotube field effect transistors performance on doping level of channel at different diameters: On/off current ratio

Appl. Phys. Lett. 99, 263104 (2011)

Planar-type In0.53Ga0.47As channel band-to-band tunneling metal-oxide-semiconductor field-effect transistors J. Appl. Phys. 110, 124505 (2011)

Enhanced rectifying response from metal-insulator-insulator-metal junctions

Appl. Phys. Lett. 99, 253503 (2011)

Interface trap density metrology from sub-threshold transport in highly scaled undoped Si n-FinFETs

J. Appl. Phys. 110, 124507 (2011)

On the role of Coulomb scattering in hafnium-silicate gated silicon $\mathrm{n}$ and $\mathrm{p}$-channel metal-oxide-semiconductorfield-effect-transistors

J. Appl. Phys. 110, 124503 (2011)

\section{Additional information on Appl. Phys. Lett.}

Journal Homepage: http://apl.aip.org/

Journal Information: http://apl.aip.org/about/about_the_journal

Top downloads: http://apl.aip.org/features/most_downloaded

Information for Authors: http://apl.aip.org/authors

\section{ADVERTISEMENT}

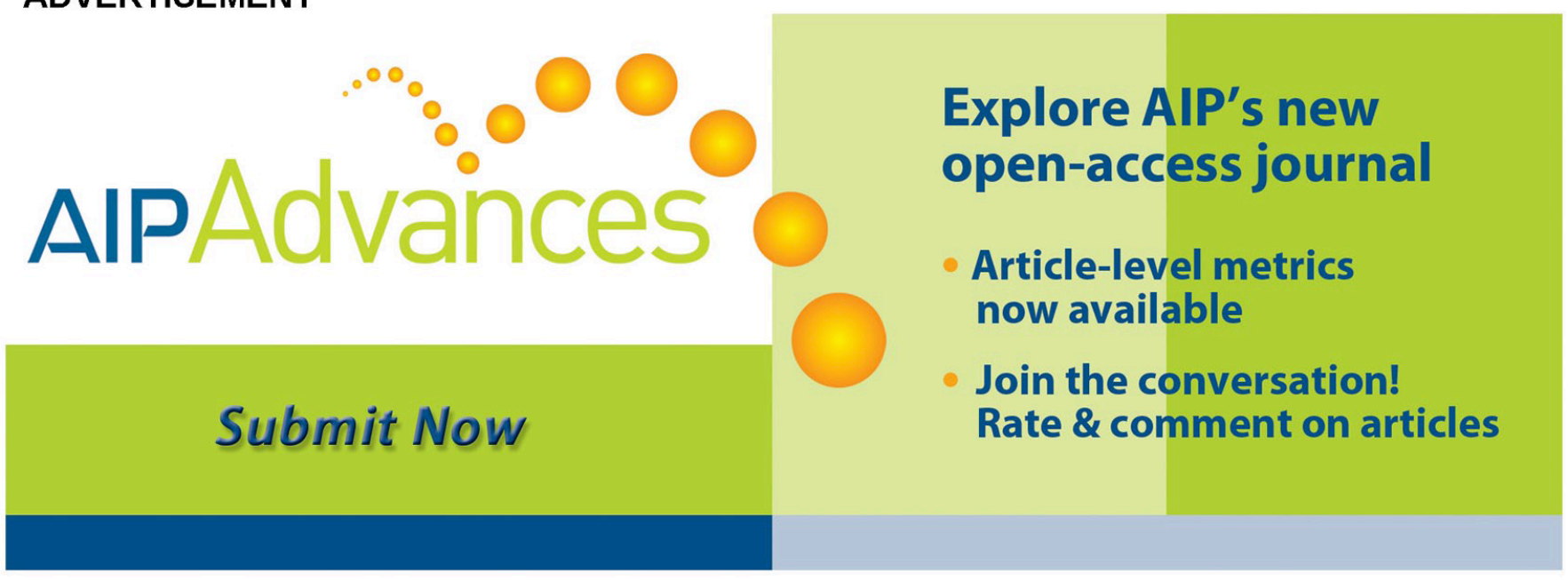




\title{
Single-step solution processing of small-molecule organic semiconductor field-effect transistors at high yield
}

\author{
Liyang Yu, ${ }^{1, a)}$ Xiaoran Li, ${ }^{2,3, b)}$ Egon Pavlica, ${ }^{4}$ Marsha A. Loth, ${ }^{5}$ John E. Anthony, \\ Gvido Bratina, ${ }^{4}$ Charlotte Kjellander, ${ }^{3}$ Gerwin Gelinck, ${ }^{3}$ and Natalie Stingelin ${ }^{1,6}{ }^{,}$ \\ ${ }^{1}$ Department of Materials and Centre for Plastic Electronics, Imperial College London, SW7 2 AZ London, \\ United Kingdom \\ ${ }^{2}$ Department of Chemical Engineering and Chemistry, Technische Universiteit Eindhoven P.O. Box 5135600 \\ $M B$ Eindhoven, The Netherlands \\ ${ }^{3}$ Holst Centre, TNO, P.O. Box 8550, 5605 KN Eindhoven, The Netherlands \\ ${ }^{4}$ Laboratory of Organic Matter Physics, University of Nova Gorica, SI-5000 Nova Gorica, Slovenia \\ ${ }^{5}$ Center for Applied Energy Research, University of Kentucky, Lexington, Kentucky 40506, USA \\ ${ }^{6}$ FRIAS, School of Soft Matter Research, University of Freiburg, 79104 Freiburg, Germany
}

(Received 26 September 2011; accepted 5 December 2011; published online 28 December 2011)

\begin{abstract}
Here, we report a simple, alternative route towards high-mobility structures of the small-molecular semiconductor 5,11-bis(triethyl silylethynyl) anthradithiophene that requires one single processing step without the need for any post-deposition processing. The method relies on careful control of the casting temperature of the semiconductor and allows rapid production of transistors with uniform and reproducible device performance over large areas. (c) 2011 American Institute of Physics. [doi:10.1063/1.3673280]
\end{abstract}

Soluble pentacenes and anthradithiophenes are promising candidates for organic field-effect transistors (OFETs): among these compounds, 5,11-bis(triethyl silylethynyl) anthradi-thiophene (TES ADT) is one of the highest performing materials with charge-carrier mobilities $\mu_{\mathrm{FET}}$ reaching $1 \mathrm{~cm}^{2} /$ Vs. ${ }^{1}$ However, obtaining reproducibly and reliably such a high performance with this small molecule is still challenging. The latter is probably best reflected by the fact that published mobility values span orders of magnitudes, and striking differences in other relevant device characteristics are also found in literature ${ }^{1-3}$ In order to overcome this undesirable feature of TES ADT, 2,8difluoro-5,11-bis(triethyl silylethynyl) anthradithiophene (diF-TES ADT) was synthesized, tailored for accelerating molecular assembly in solution through halogen interactions (which result from the introduction of difluoro-moieties into the fused-aromatic backbone). ${ }^{4}$ This adjusted molecular design significantly increased the reproducibility in obtaining thin-film structures of good semiconducting properties, and device performance and uniformity could be enhanced further when the material was blended with a polymer matrix, such as the semiconducting polytriarylamines (PTAAs). ${ }^{5}$ However, high-performance transistors were mostly obtained in top-gate devices, in combination with relatively thick polymer gate dielectrics of a low dielectric constant, where circuitry integration can be complex, and the low capacitance between gate electrode and semiconducting channel implies high driving voltages. The reason for the need for top-gate configuration is that device performance of such blends relies on vertical phase segregation of the small molecule to the top surface (i.e., towards the dielectric interface)—which is usually difficult to control, especially over large areas. Since, in addition, the synthetic route of diF-TES ADT is significantly more intricate com-

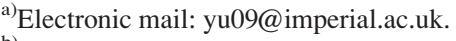

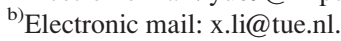

pared to the non-fluorinated TES ADT, we revisited the use of TES ADT in OFET applications, focusing on single component systems and the technologically desired bottomgate/bottom-contact transistor configuration.

Recent work has indicated that following such a strategy of using single component TES ADT active layers in bottomgate/bottom-contact devices may be a feasible option. Most prominently, Cho et al. exploited "aging" (i.e., crystallization over time) of an initial vitreous solid state of low mobility $\left(\mu_{\mathrm{FET}} \sim 0.002 \mathrm{~cm}^{2} / \mathrm{Vs}\right)$ to realize well performing structures. However, in order to obtain $\mu_{\mathrm{FET}} \sim 0.1 \mathrm{~cm}^{2} / \mathrm{Vs}$ with such TES ADT architectures, the material needed to be aged over a period of at least 7 days in vacuum. ${ }^{3}$

Whilst "aging" (or crystallization in the solid state) does provide an elegant method for studying relevant structure/device performance interrelationships of TES ADT films, it is evident that this protocol may not lead to high-throughput device manufacturing. We, therefore, explored whether the molecular order of TES ADT can be manipulated without the need to rely on time-consuming post-processing procedures. To this end, in a first set of experiments, we fabricated transistor devices on $\mathrm{Si}\left(\mathrm{n}^{++}\right) / \mathrm{SiO}_{2}$ substrates comprising an oxide dielectric of $140 \mathrm{~nm}$-thickness and photo-lithographically patterned Au source/drain electrodes. Prior to device fabrications, a pentafluorobenzenethiol monolayer was deposited onto the Au electrodes. ${ }^{6}$ The $\mathrm{SiO}_{2}$ was treated with trichlorophenylsilane. Our objective was to investigate if casting at temperatures above the glass transition temperature $T_{\mathrm{g}}$ (see Ref. 3) directly leads to aged structures. For this purpose, we used 4 wt. \% TES ADT solutions in chloroform and solution-cast them at $T_{\text {casting }}$ $\sim 30-40^{\circ} \mathrm{C}$. Our reasoning was based on the fact that aging is a process that occurs at temperatures close to or above the glass transition temperature $T_{\mathrm{g}}$ of a given material, and thus, hightemperature casting may accelerate this process. [Note that aging at elevated temperatures has been observed to occur in films of other small molecular semiconductors such as $\mathrm{N}, \mathrm{N}^{\prime}$-diphenyl-N,N'-bis(3-methylphenyl)-(1,1'-biphenyl)-4,4'-diamine 
(TPD). ${ }^{7}$ It is also commonly found in bulk commodity polymer products. ${ }^{8}$ ]

Predominantly amorphous structures were obtained when following this processing protocol, which were very similar to the spin-coated, low-mobility films reported by Cho et al. The amorphous nature of such "high-temperature cast" TES ADT films is evident from the absence of any birefringence or detectable reflections in, respectively, the optical microscopy and wide-angle x-ray scattering (WAXS) data presented in Fig. 1. As a consequence of the high molecular disorder in such high-temperature cast TES ADT structures, bottom-gate/bottom-contact devices displayed a saturation charge-carrier mobility of only $5 \times 10^{-6} \mathrm{~cm}^{2} / \mathrm{Vs}$, in agreement with Ref. 3 .

We attribute formation of an amorphous structure at least partly to the rapid solvent removal and, hence, limited solidification time of TES ADT. This counter-acts the higher molecular mobility at elevated temperatures that could have led to an improved molecular arrangement in the resulting TES ADT structure. In order to decrease the solidification rate, in a second set of experiments, we, therefore, cast the TES ADT solution at $5{ }^{\circ} \mathrm{C}$, which can be expected to reduce the solvent evaporation rate. Highly birefringent TES ADT films were obtained in this manner. These films featured well-defined diffraction peaks of a full-width-at-half-maxima of less than $0.014 \AA^{-1}$ in agreement with the formation of a high-quality thin film. Most intriguingly, these lowtemperature cast TES ADT architectures were homogenous and uniform over the entire substrate area. [Note, casting at $25^{\circ} \mathrm{C}$ led to a "mixed" microstructure comprised of amorphous domains interspersed in birefringent regions (Fig. 1/ left: middle panel)].

The highly homogenous nature of films cast at $5{ }^{\circ} \mathrm{C}$ allowed us to fabricate bottom-gate/bottom-contact devices in a single step, with the resulting devices out-performing any single-component OFET based on TES ADT, independent of device architecture ${ }^{1-3}$ as recorded over 90 transistors (Fig. 2). All transistors displayed steep sub-threshold slopes and high current modulation on the order of magnitude of

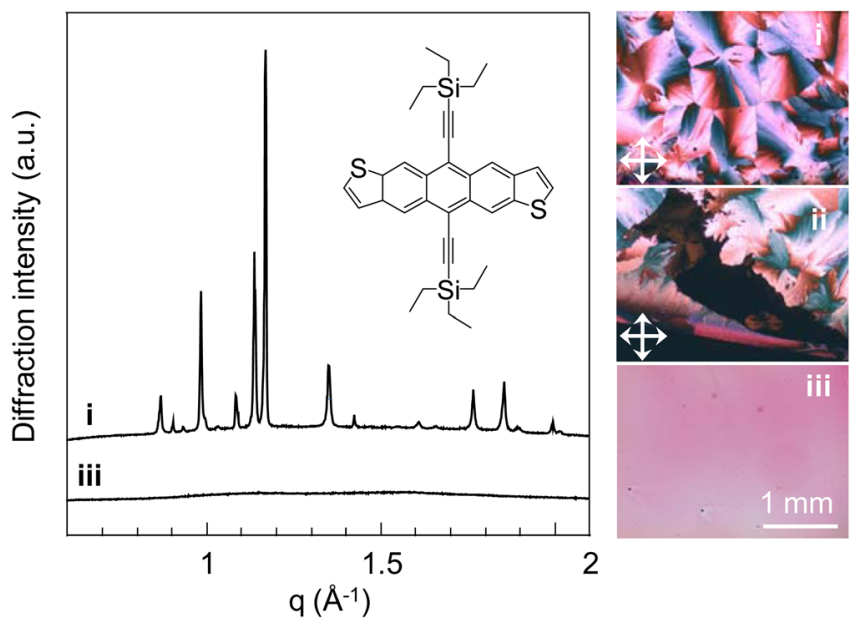

FIG. 1. (Color online) Left: Wide-angle x-ray diffractograms of TES ADT powders obtained from thin films cast at $5^{\circ} \mathrm{C}$ (i) and $40^{\circ} \mathrm{C}$ (iii), respectively. In the inset, the chemical structure of TES ADT is shown. Right: Optical micrographs of TES ADT thin films, solution-cast at, respectively, $5{ }^{\circ} \mathrm{C}$ (top; crossed-polarized - i), room temperature (middle; crossed-polarized ii), and $40^{\circ} \mathrm{C}$ (bottom; unpolarized - iii).
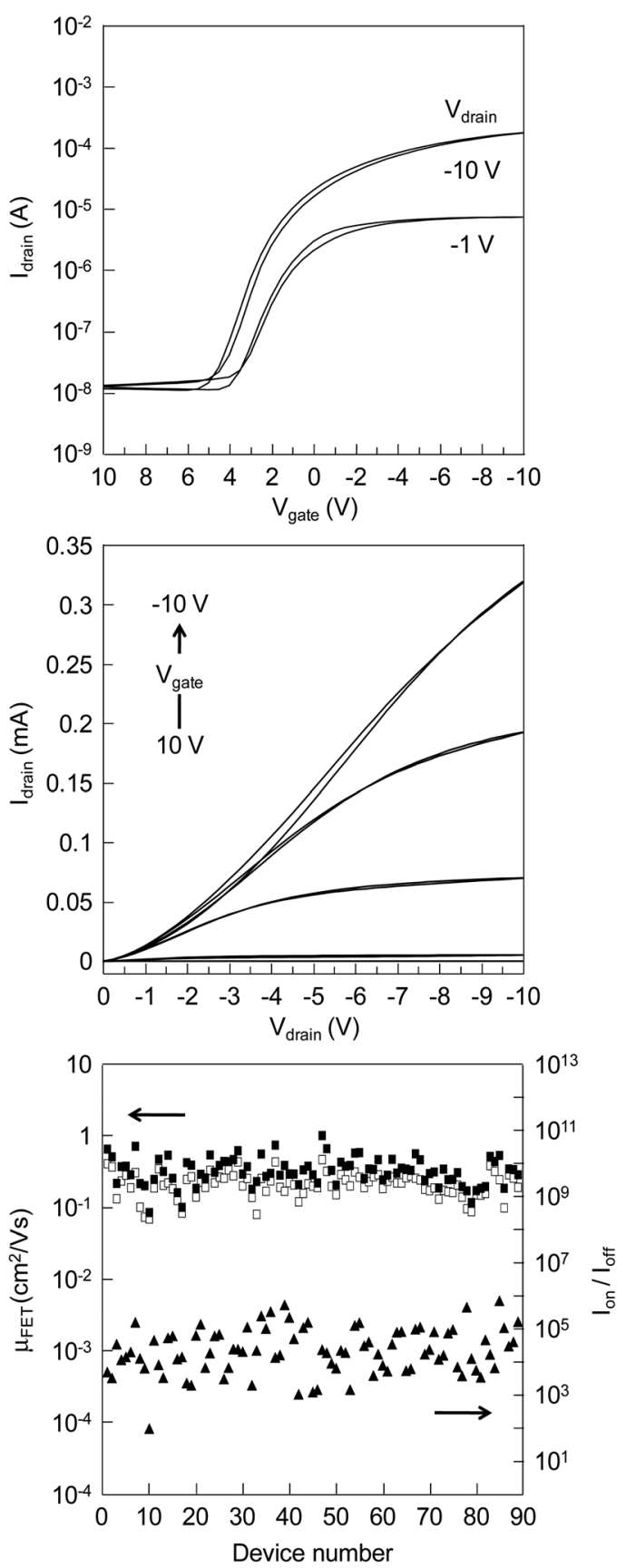

FIG. 2. Top/middle panel: Typical OFET transfer (top) and output (middle) characteristics of "low-temperature"-cast TES ADT thin films, measured in a bottom-contact/bottom-gate configuration. Bottom panel: Charge-carrier mobilities and ON/OFF ratios deduced from 90 devices that had been cast at low temperatures.

$10^{5}$ at low operating voltage of $-5 \mathrm{~V}$ and less desired qualities for applications such as switching devices for display backplanes. We deduce high saturation mobilities of $0.42 \pm 0.19 \mathrm{~cm}^{2} / \mathrm{Vs}$ and observe stable threshold voltages of $3.6 \pm 0.9 \mathrm{~V}$. The best device reached a saturation mobility of $1.3 \mathrm{~cm}^{2} / \mathrm{Vs}$. Most beneficially, the device yield is $100 \%$, which promises reliable manufacturing and simplified device integration, especially when considering that our single-step process has already allowed us to produce homogenous films of more than a square centimeter size.

The above transistor data are supported by lateral timeof-flight transient photoconductivity measurements (ITOF), which provide an alternative tool to analyse in-plane charge 
transport. $^{9,10}$ We applied biases from $200 \mathrm{~V}$ to $800 \mathrm{~V}$ between co-planar electrodes separated by $160 \mu \mathrm{m}$ (rather than using a diode structure employed in more conventional TOF). Consistently, charge-carrier mobilities of $0.08 \mathrm{~cm}^{2} / \mathrm{Vs}$ for the crystalline, "low-temperature cast" TES ADT films can be deduced from the ITOF data. These values are comparable to the mobilities measured for the bottom-gate/bottomcontact transistors fabricated following the same processing protocol; and the small difference in the observed chargecarrier mobilities can be attributed to the different chargecarrier densities that can be induced in FETs compared to ITOF measurements. ${ }^{10}$ For the amorphous structures, cast above the glass transition temperature, ${ }^{3}$ we measure ITOF mobilities that are four orders of magnitude lower $\left(\mu_{\mathrm{TOF}}\right.$ of $\left.6 \times 10^{-6} \mathrm{~cm}^{2} / \mathrm{Vs}\right)$, again in good agreement with our device data.

In summary, when casting TES ADT solutions in chloroform at temperatures of more than $20^{\circ} \mathrm{C}$ below the material's glass transition temperature, highly crystalline thin films are realized by a single-step process. This allows reliable fabrication of high-performance bottom-gate/bottom-contact transistors as scrutinized based on device data obtained over 90 FET structures. We believe that our strategy is also likely to work for other organic semiconductors and that strict control of processing conditions, such as casting temperature will lead to further progress in the field of organic transistors.

We are very grateful to the UK's Engineering and Physical Sciences Research Council and the Dutch Polymer Institute (LATFE programme) for financial support and also acknowledge the EC's 7th Framework Program ONE-P project (Grant Agreement 212311) for funding.

${ }^{1}$ M. M. Payne, S. R. Parkin, J. E. Anthony, C.-C. Kuo, and T. N. Jackson, J. Am. Chem. Soc. 127, 4986 (2005).

${ }^{2}$ K. C. Dickey, J. E. Anthony, and Y.-L. Loo, Adv. Mater. 18, 1721 (2006).

${ }^{3}$ W. H. Lee, J. A. Lim, D. H. Kim, J. H. Cho, Y. Jang, Y. H. Kim, J. I. Han, and K. Cho, Adv. Funct. Mater. 18, 560 (2008).

${ }^{4}$ S. Subramanian, S. K. Park, S. R. Parkin, V. Podzorov, T. N. Jackson, and J. E. Anthony, J. Am. Chem. Soc. 130, 2706 (2008).

${ }^{5}$ R. Hamilton, J. Smith, S. Ogier, M. Heeney, J. E. Anthony, I. McCulloch, J. Veres, D. D. C. Bradley, and T. D. Anthopoulos, Adv. Mater. 21, 1166 (2009).

${ }^{6}$ M. M. Payne, S. R. Parkin, J. E. Anthony, C.-C. Kuo, and T. N. Jackson, J. Am. Chem. Soc. 127, 4986 (2005).

${ }^{7}$ E. M. Han, L. M. Do, M. Fujihira1, H. Inada, and Y. Shirota, J. Appl. Phys. 80, 3297 (1996).

${ }^{8}$ B. Wunderlich, Macromolecular Physics Vol. 2: Crystal Nucleation, Growth, Annealing (Academic, New York, 1976).

${ }^{9}$ E. Pavlica and G. Bratina, J. Phys. D: Appl. Phys. 41, 135109 (2008).

${ }^{10}$ See supplementary material at http://dx.doi.org/10.1063/1.3673280 for details on the lateral time-of-flight (ITOF) photoconductivity technique and ITOF data. 